\title{
Mesalamine-Induced Myocarditis and Coronary Vasculitis in a Pediatric Ulcerative Colitis Patient: A Case Report
}

\author{
Elimarys Perez-Colon, ${ }^{1}$ Gul H. Dadlani, ${ }^{1,2}$ Ivan Wilmot, ${ }^{2}$ and Michelle Miller ${ }^{2}$ \\ ${ }^{1}$ Department of Pediatrics, University of South Florida, 2 Tampa General Circle, Tampa, FL 33606, USA \\ ${ }^{2}$ All Children's Hospital Heart Institute, Outpatient Care Center, 2nd Floor, 501 6th Street South Saint. Petersburg, FL 33701, USA
}

Correspondence should be addressed to Elimarys Perez-Colon, eperezco@health.usf.edu

Received 7 September 2011; Accepted 17 October 2011

Academic Editors: E. Czkwianianc, V. Ertekin, D. Fischer, E. Hon, and D. I. Zafeiriou

Copyright (C) 2011 Elimarys Perez-Colon et al. This is an open access article distributed under the Creative Commons Attribution License, which permits unrestricted use, distribution, and reproduction in any medium, provided the original work is properly cited.

\begin{abstract}
Mesalamine-containing products are often a first-line treatment for ulcerative colitis. Severe adverse reactions to these products, including cardiovascular toxicity, are rarely seen in pediatric patients. We present a case of a 16-year-old boy with ulcerative colitis treated with Asacol, a mesalamine-containing product, who developed sudden onset chest pain after four weeks on therapy. Serial electrocardiograms showed nonspecific ST segment changes, an echocardiogram showed mildly decreased left ventricular systolic function with mild to moderate left ventricular dilation and coronary ectasia, and his troponins were elevated. Following Asacol discontinuation, his chest pain resolved, troponins were trending towards normal, left ventricular systolic function normalized, and coronary ectasia improved within 24 hours suggesting an Asacol-associated severe drug reaction. Mesalamine-induced cardiovascular toxicity, although rare, may represent a life-threatening disorder. Therefore, every patient presenting with acute chest pain should receive a workup to rule out this rare drug-induced disorder.
\end{abstract}

\section{Introduction}

Mesalamine-(5-aminosalicylic acid) containing products are a well-known treatment for inflammatory bowel disease, often as first line. Mesalamine's mechanism of action is not completely understood, but seems to reduce colonic inflammation topically by inhibiting the cyclooxygenase pathway and the $\gamma$-form of peroxisomal proliferator-activated receptors (PPAR- $\gamma$ ) signaling pathway. Adverse reactions to mesalamine are uncommon and include mostly gastrointestinal upset and headaches [1]. Rare drug reactions to mesalamine have been described in the literature and include pancreatitis, blood dyscrasias, cardiovascular problems, and interstitial nephritis [2]. Although rare, pericarditis, myocarditis, vasculitis, and left ventricular dysfunction have been described with mesalamine therapy [3-8]. We present a case of myocarditis with coronary vasculitis as a reaction to a mesalamine product, Asacol.

\section{Case Presentation}

This is a case of a 16-year-old Hispanic male without significant past medical history admitted for evaluation follow- ing 3-month history of abdominal pain and bloody diarrhea. Outpatient pediatric gastroenterology evaluation was negative for infectious causes, and due to ongoing symptoms, he was admitted for further evaluation and treatment. Colonoscopy performed on admission showed pancolitis with friable tissue, and biopsies were taken confirming ulcerative colitis (UC) as the diagnosis. He was started on methylprednisolone $0.5 \mathrm{mg} / \mathrm{kg} / \mathrm{dose}$ twice a day and Asacol $400 \mathrm{mg}$ three times a day $(30 \mathrm{mg} / \mathrm{kg} /$ day $)$. His symptoms persisted, and on hospital day number four his Asacol dose was increased to $800 \mathrm{mg}$ three times per day $(60 \mathrm{mg} / \mathrm{kg} /$ day $)$. His abdominal pain and bloody diarrhea started to improve on the new regimen up until hospital day nine when he developed worsening of symptoms with an acute episode of bright red blood per rectum. At that point, Azathioprine $4 \mathrm{mg} / \mathrm{kg} /$ day was added and the patient was started on total parenteral nutrition. On hospital day number ten, he developed a right upper arm superficial thrombosis with superimposed methicillin-sensitive Staphylococcus thrombophlebitis. Hematology was involved, and he was started on anticoagulation therapy with low-molecularweight heparin (LMWH) and cefazolin. A hypercoagulable 


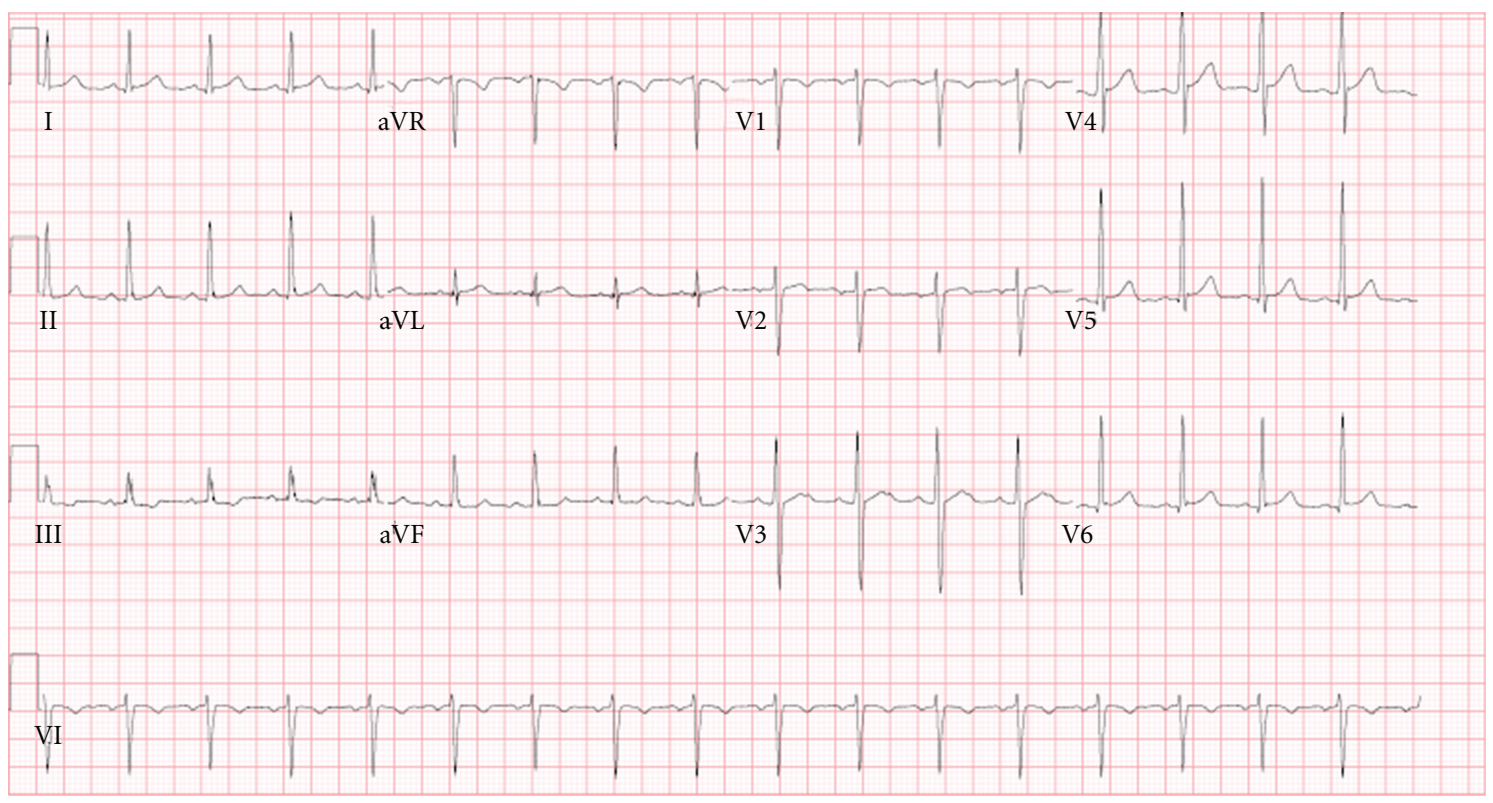

FIGURE 1: Electrocardiogram on day of chest pain onset: sinus tachycardia with no ST segment changes.

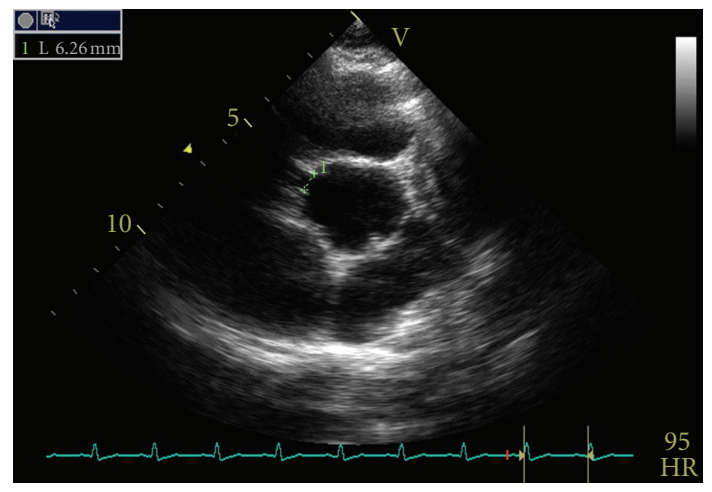

(a)

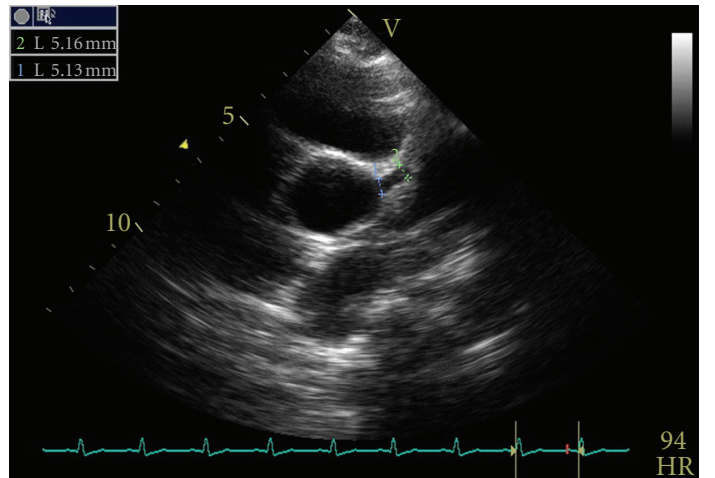

(b)

FIGURE 2: Coronary artery ectasia. Right coronary artery diameter measuring $6 \mathrm{~mm}$ (a) and left coronary artery diameter measuring $5 \mathrm{~mm}$ (b).

workup, including prothrombin 2021A, factor 5 Leiden mutation, homocysteine, anticardiolipin antibody, protein C, protein S, lupus anticoagulant, and Antithrombin III, was obtained and resulted negative. On hospital day eleven, he was noted to have intermittent systemic hypertension. Pediatric nephrology was consulted, and a renal ultrasound was noted to be normal without renal artery thrombosis or stenosis. His renal function was within normal limits, and he was started on nifedipine as needed for systolic blood pressure greater than $150 \mathrm{mmHg}$. His elevated blood pressure was thought to be secondary to steroids. Over the course of the hospitalization, his platelets began to drop and on hospital day number fifteen he had a large episode of hematochezia and some epixtasis. At that point, the LMWH was stopped and he received packed red blood cells and platelet transfusions. Due to persistent thrombocytopenia with poor response to platelet transfusion, he underwent a bone marrow aspirate that showed cellular marrow with active hematopoiesis. He was diagnosed with idiopathic thrombocytopenic purpura (ITP) with positive antiplatelets antibodies and was treated with intravenous immunoglobulin (IVIG), 1 gram/kilogram/day, without major events.

On hospital day number twenty-nine, he developed acute chest pain described as throbbing pain located in the middle of his chest without radiation. His physical exam was unremarkable except for elevated blood pressure at $152 / 91 \mathrm{mmHg}$ and tachycardia with heart rate of 109 . His electrocardiogram showed sinus tachycardia without ST segment changes (Figure 1). His troponin-I was elevated and peaked at $0.67 \mathrm{ng} / \mathrm{mL}$, and cardiology was consulted.

A transthoracic echocardiogram revealed mild to moderate dilated left ventricle, mild left ventricular systolic dysfunction with an ejection fraction (EF) of $48 \%$, and bilateral coronary artery ectasia (Figure 2). His right coronary artery 
TABLE 1: Correlation of symptoms progression and diagnostic data on and off Asacol.

\begin{tabular}{|c|c|c|c|c|c|}
\hline & $\begin{array}{l}\text { On Asacol } \\
\text { day } 29\end{array}$ & $\begin{array}{l}\text { Off Asacol } \\
\text { day } 1\end{array}$ & $\begin{array}{l}\text { Off Asacol } \\
\text { day } 2\end{array}$ & $\begin{array}{l}\text { Off Asacol } \\
\text { day } 3\end{array}$ & $\begin{array}{l}\text { Off Asacol } \\
\text { day } 7\end{array}$ \\
\hline Symptoms & Chest pain & Chest pain & None & None & None \\
\hline \multirow{3}{*}{ Troponin } & $0.157 \mathrm{ng} / \mathrm{mL}$ & $0.466 \mathrm{ng} / \mathrm{L}$ & $0.341 \mathrm{ng} / \mathrm{mL}$ & $0.148 \mathrm{ng} / \mathrm{mL}$ & $<0.010 \mathrm{ng} / \mathrm{mL}$ \\
\hline & $0.447 \mathrm{ng} / \mathrm{mL}$ & $0.406 \mathrm{ng} / \mathrm{mL}$ & & & \\
\hline & $0.67 \mathrm{ng} / \mathrm{mL}$ & & & & \\
\hline EKG & $\begin{array}{l}\text { Sinus Tachycardia } \\
\text { With no ST segment } \\
\text { Changes (Figure 1) }\end{array}$ & $\begin{array}{l}\text { Normal sinus } \\
\text { rhythm with } \\
\text { nonspecific ST } \\
\text { changes in inferior } \\
\text { leads (Figure 4) }\end{array}$ & $\begin{array}{l}\text { Normal sinus } \\
\text { rhythm with } \\
\text { nonspecific ST } \\
\text { changes }\end{array}$ & $\begin{array}{l}\text { Normal sinus } \\
\text { rhythm with sinus } \\
\text { arrhythmia and no } \\
\text { ST segment Changes }\end{array}$ & $\begin{array}{l}\text { Normal sinus } \\
\text { rhythm with sinus } \\
\text { arrhythmia and T } \\
\text { wave inversion in } \\
\text { lead III (Figure 5) }\end{array}$ \\
\hline \multirow[b]{3}{*}{$\mathrm{ECHO}$} & $\begin{array}{l}\text { Mild-moderate } \\
\text { dilated LV }\end{array}$ & Mildly dilated LV & Mildly dilated LV & Mildly dilated LV & Normal LV \\
\hline & $\mathrm{EF}$ at $48 \%$ & EF at $65 \%$ & $\mathrm{EF}$ at $59 \%$ & $\mathrm{EF}$ at $56 \%$ & $\mathrm{EF}$ at $66 \%$ \\
\hline & $\begin{array}{l}\text { Dilated coronary } \\
\text { arteries } \\
\text { RCA } 6 \mathrm{~mm}(\mathrm{Z} \geq+4) \\
\text { LCA } 5 \mathrm{~mm} \\
(\mathrm{Z}=+2) \text {. }\end{array}$ & $\begin{array}{l}\text { Proximal dilation of } \\
\text { coronary arteries }\end{array}$ & $\begin{array}{l}\text { Proximal dilation of } \\
\text { coronary arteries } \\
\text { RCA } 6.1 \mathrm{~mm}\end{array}$ & $\begin{array}{l}\text { Proximal dilation of } \\
\text { coronary arteries } \\
\text { RCA } 4.5 \mathrm{~mm} \\
\text { LCA } 5 \mathrm{~mm} \\
\text { LDA } 3.4 \mathrm{~mm}\end{array}$ & $\begin{array}{l}\text { Proximal dilation of } \\
\text { coronary arteries } \\
\text { RCA } 3.8 \mathrm{~mm} \\
\text { LCA } 4.8 \mathrm{~mm} \\
\text { LDA } 3.6 \mathrm{~mm} \\
\end{array}$ \\
\hline
\end{tabular}

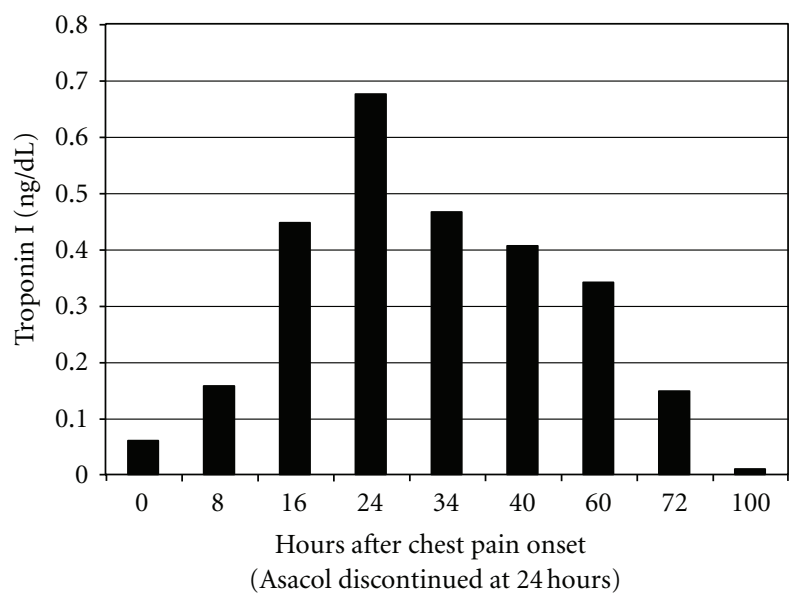

Figure 3: Cardiac enzymes trend on and off Asacol.

measured $6 \mathrm{~mm}$ in diameter, and the left main coronary artery was $5 \mathrm{~mm}$ in diameter. He was noted to have normal intracardiac anatomy. He was transferred to the pediatric intensive care unit for close cardiovascular monitoring. A decision to discontinue Asacol was made on hospital day thirty, since it was thought to be the most likely etiology of his symptoms. After Asacol discontinuation, his chest pain resolved and his troponins were noted to trend towards normal (Figure 3).

An electrocardiogram on hospital day one off Asacol showed normal sinus rhythm with nonspecific ST segment changes in the inferior leads (Figure 4). A repeated echocardiogram showed improved left ventricular function with an EF of 59\% and improved coronary artery dilation after two days off Asacol. An echocardiogram performed three days following Asacol discontinuation showed mild dilatation of the left ventricle with normal systolic function (EF 56\%) and improved coronary artery dilation, although there was mild persistent proximal dilation. His EKG showed normal sinus rhythm with nonspecific ST segments changes. His troponin-I continued to trend down, and he was discharged home. He was seen on followup after a week of Asacol discontinuation, and his electrocardiogram showed normal sinus rhythm with $\mathrm{T}$ wave inversion in lead III (Figure 5). His echocardiogram showed mildly dilated left ventricle with an ejection fraction of $66 \%$ and mildly improved proximal dilation of the coronary arteries. His right coronary artery measured $3.8 \mathrm{~mm}$, and his left main coronary artery measured $4.8 \mathrm{~mm}$.

\section{Discussion}

Cardiac complications in patients with inflammatory bowel disease may represent a rare extraintestinal manifestation or drug-related side effect [3, 7]. Cardiac manifestations of ulcerative colitis (UC) are uncommon and include pericarditis, pericardial effusion, and few cases of pericardiac tamponade. UC-associated pericarditis is a diagnosis of exclusion after metabolic causes, infection, malignancy, and connective tissue disorders have been ruled out [9]. Mesalamine-(5aminosalicylic acid) induced cardiovascular toxicity, including pericarditis, myocarditis, vasculitis, and left ventricular dysfunction, is a rare complication that has been described in the literature [3-8]. Mesalamine's mechanism of action is not fully understood and includes inhibition of the cyclooxygenase pathway and therefore decreased prostaglandins synthesis and inhibition of the PPAR- $\gamma$ signaling pathway resulting in decreased activity of nuclear factor $\kappa \mathrm{B}$ and as a consequence decreased inflammation in the colon $[3,10]$. The specific mechanism for mesalamine-induced cardiovascular toxicity is not completely understood but is thought to be a hypersensitivity reaction rather than a cytotoxic effect. A proposed mechanism is humoral-mediated hypersensitivity in which antibodies formed against mesalamine cross-react 


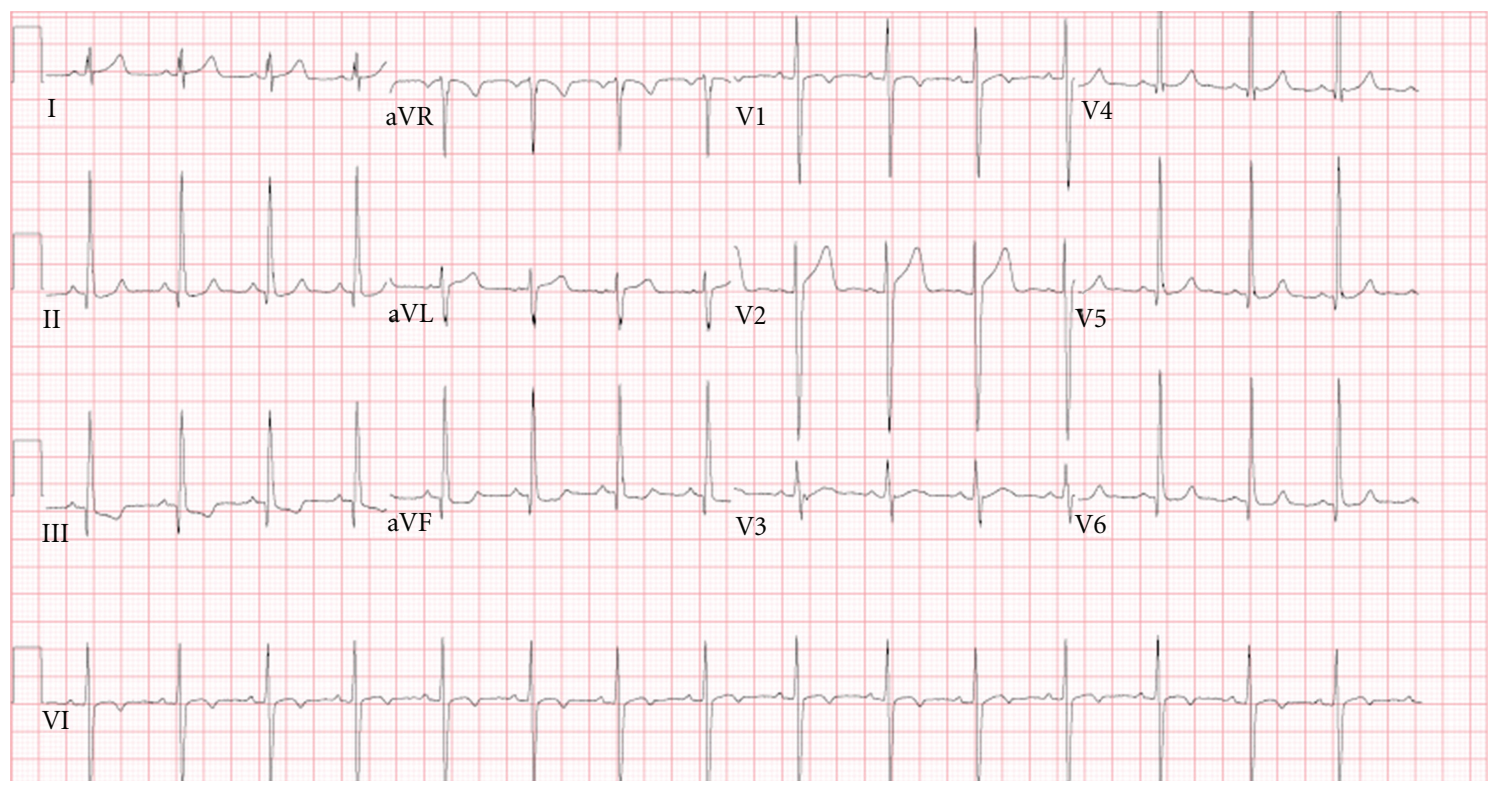

FIGURE 4: Electrocardiogram 6 hours off Asacol: normal sinus rhythm and nonspecific ST changes.

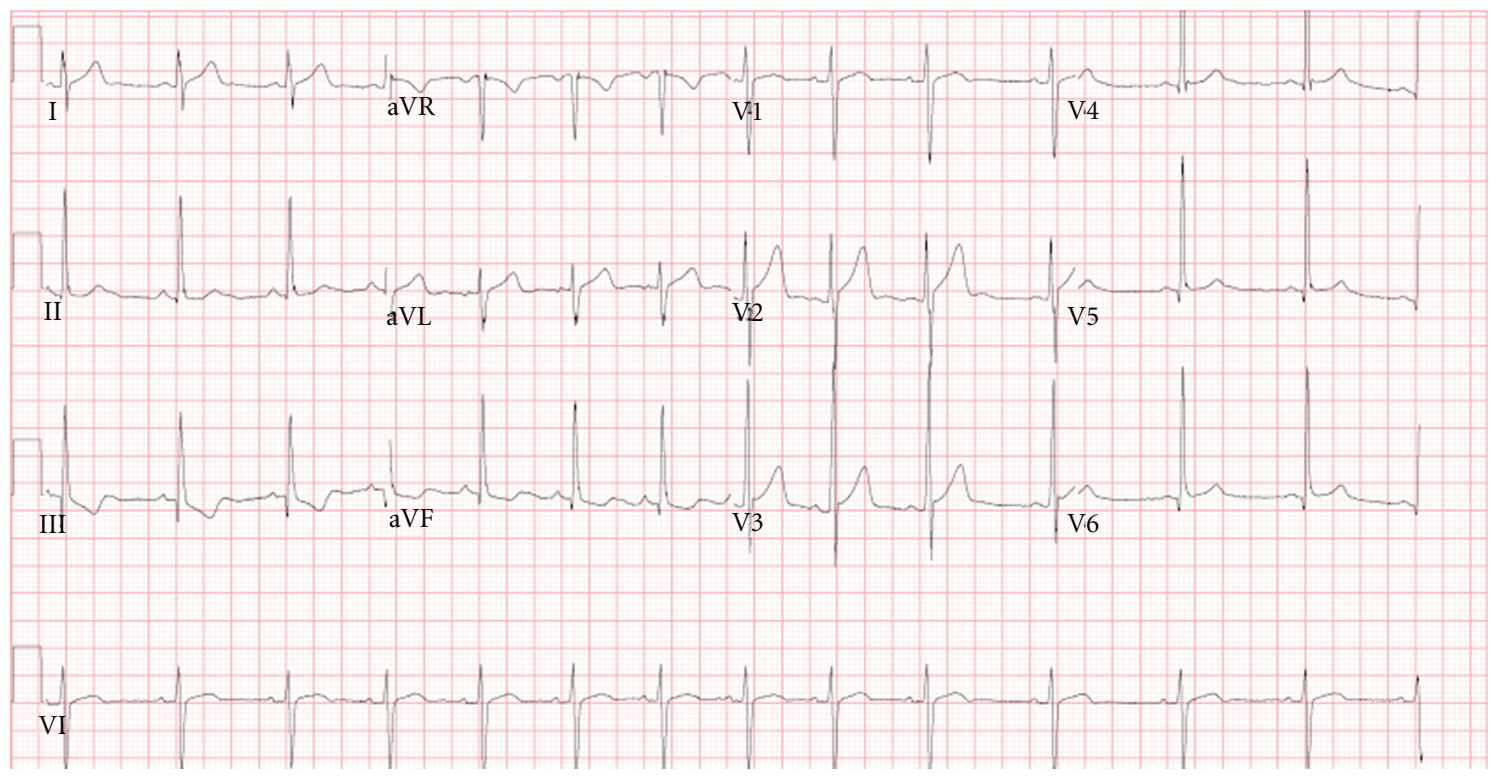

FIGURE 5: Electrocardiogram 7 days off Asacol: normal sinus rhythm and T wave inversion lead III.

with cardiac tissue causing inflammation [8]. Most cases of mesalamine-induced cardiovascular toxicity occur 24 weeks after the initial exposure to the drug, although presentation may be delayed in the setting of concomitant steroid administration [8]. Resolution of symptoms has occurred in all reported cases within one week after drug discontinuation.

In our case, the patient's onset and resolution of symptoms and signs are similar to those reported in the literature. Within twenty-four hours after Asacol discontinuation, our patient had normalized left ventricular function (Table 1), making mesalamine-induced myocarditis the most likely diagnosis. Coronary artery ectasia, seen in our patient, has been previously described in a similar case in the literature and may represent a vasculitis type inflammation induced by mesalamine by a mechanism similar to the one described above. Although improved after Asacol discontinuation, mild proximal coronary ectasia persisted one week following Asacol discontinuation. We will continue to follow this finding for further correlation.

Our patient also received IVIG during his hospital stay for ITP, and there are several cases of non-ST elevation as well as ST elevation myocardial infarction described in the adult literature in patients with prior risk factors for cardiovascular disease (i.e., hypertension, diabetes, and coronary artery disease) after a first cycle of IVIG; this is likely secondary to 
hyperviscosity and complement activation causing occlusion of vessels already narrowed by atherosclerosis [11-13]. Our patient did not have any risk factor for cardiovascular disease and his chest pain presented a week after the IVIG infusion. There are also no reported cases in the pediatric population making IVIG a very unlikely suspect.

Mesalamine-induced cardiovascular toxicity, although rare, may represent a life-threatening disorder that requires immediate discontinuation of the mesalamine-containing product and adequate supportive treatment. It is suggested that every patient, on mesalamine, presenting with acute chest pain, shortness of breath, or any additional cardiovascular concern undergoes an electrocardiogram, cardiac enzymes, and an echocardiogram to rule out this rare druginduced disorder.

\section{References}

[1] M. L. Scribano, "Adverses effects of IBD therapies," Inflammatory Bowel Diseases, vol. 14, no. S2, pp. 210-211, 2008.

[2] E. V. Loftus Jr., S. V. Kane, and D. Bjorkman, "Systematic review: short-term adverse effects of 5-aminosalicylic acid agents in the treatment of ulcerative colitis," Alimentary Pharmacology and Therapeutics, vol. 19, no. 2, pp. 179-189, 2004.

[3] O. Atay, K. Radhakrishnan, J. Arruda, and R. Wyllie, "Severe chest pain in a pediatric ulcerative colitis patient after 5aminosalicylic acid therapy," World Journal of Gastroenterology, vol. 14, no. 27, pp. 4400-4402, 2008.

[4] L. Garcia-Ferrer, J. Estornell, and V. Palanca, "Myocarditis by mesalazine with cardiac magnetic resonance imaging," European Heart Journal, vol. 30, no. 8, p. 1015, 2009.

[5] N. Ishikawa, T. Imamura, K. Nakajima et al., "Acute pericarditis associated with 5-aminosalicylic acid (5-ASA) treatment for severe active ulcerative colitis," Internal Medicine, vol. 40, no. 9, pp. 901-904, 2001.

[6] L. Doganay, B. Akinci, N. Pekel, I. Simsek, and H. Akpinar, "Mesalazine-induced myopericarditis in a patient with ulcerative colitis," International Journal of Colorectal Disease, vol. 21, no. 2, pp. 199-200, 2006.

[7] O. Merceron, C. Bailly, and A. Khalil, "Mesalamine induced Myocarditis," Cardiology Research and Practice, vol. 2010, Article ID 930190, 3 pages, 2010.

[8] R. A. Waite and J. M. Malinowski, "Possible mesalamineinduced pericarditis: case report and literature review," Pharmacotherapy, vol. 22, no. 3, pp. 391-394, 2002.

[9] A. Rezaie, K. Wong, and G. Gyenes, "Pericardial Tamponade in a patient with inactive Ulcerative Colitis," Case Reports in Medicine, vol. 2010, Article ID 3524173, 3 pages, 2010.

[10] H. Kim, H. Jeon, H. Kong et al., "A molecular mechanism for the anti-inflammatory effect of taurine-conjugated 5aminosalicylic acid in inflamed colon," Molecular Pharmacology, vol. 69, no. 4, pp. 1405-1412, 2006.

[11] M. Mizrahi, T. Adar, E. Orenbuch-Harroch, and Y. Elitzur, "Non-ST elevation Myocardial infarction after high dose intravenous immunoglobulin infusion," Case Reports in Medicine, vol. 2009, Article ID 861370, 4 pages, 2009.

[12] D. Singh-Grewal, A. Kemp, and M. Wong, "A prospective study of the immediate and delayed adverse events following intravenous immunoglobulin infusions," Archives of Disease in Childhood, vol. 91, no. 8, pp. 651-654, 2006.
[13] S. B. Stenton, D. Dalen, and K. Wilbur, "Myocardial infarction associated with intravenous immune globulin," Annals of Pharmacotherapy, vol. 39, no. 12, pp. 2114-2118, 2005. 


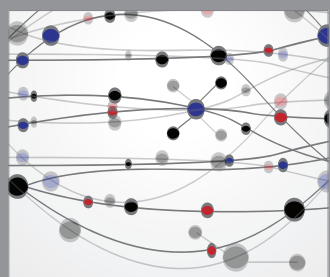

The Scientific World Journal
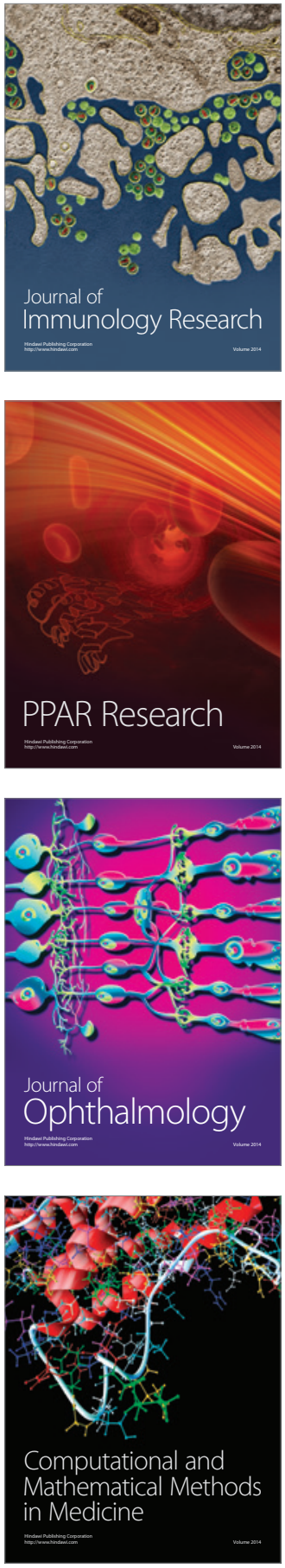

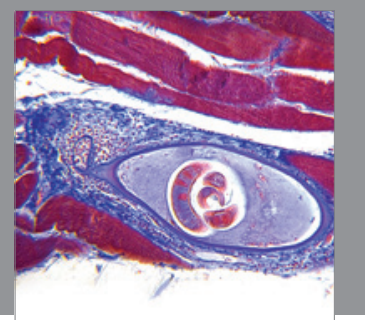

Gastroenterology

Research and Practice
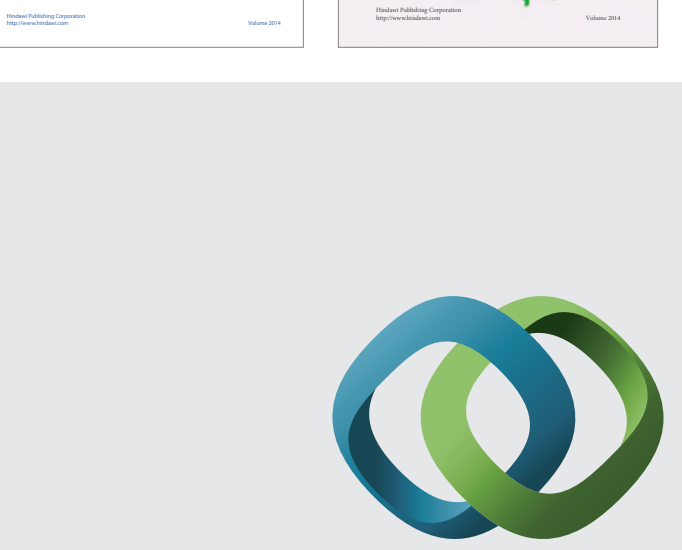

\section{Hindawi}

Submit your manuscripts at

http://www.hindawi.com
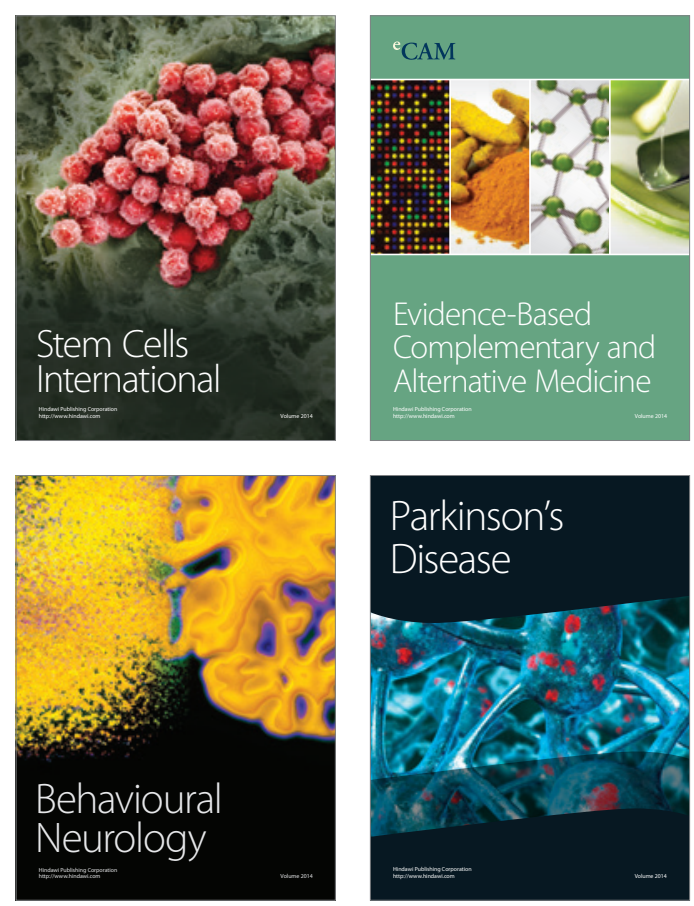

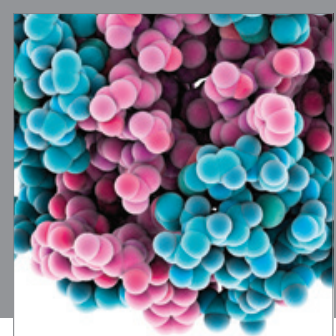

Journal of
Diabetes Research

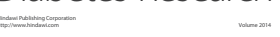

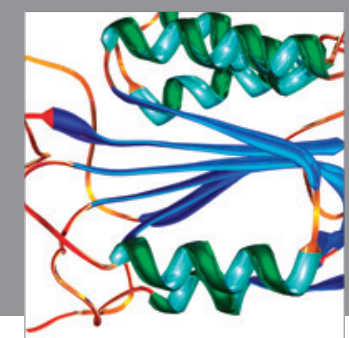

Disease Markers
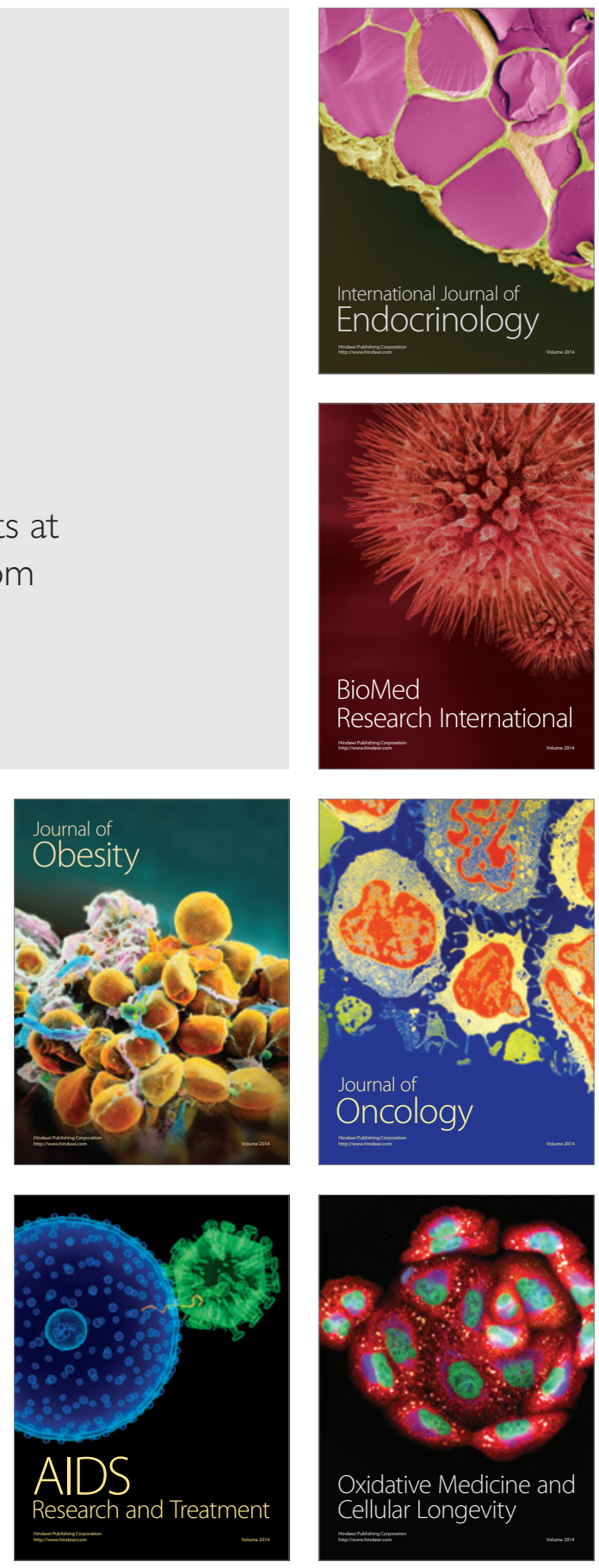